\title{
Gpr1 is an active chemerin receptor influencing glucose homeostasis in obese mice
}

\author{
Jillian L Rourke, Shanmugam Muruganandan, Helen J Dranse, Nichole M McMullen \\ and Christopher J Sinal
}

Department of Pharmacology, Faculty of Medicine, Dalhousie University, 5850 College Street, PO Box 15000, Halifax, Nova Scotia, Canada B3H 4R2

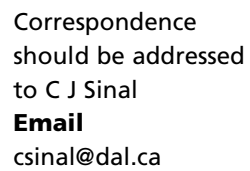

\begin{abstract}
Chemerin is an adipose-derived signaling protein (adipokine) that regulates adipocyte differentiation and function, immune function, metabolism, and glucose homeostasis through activation of chemokine-like receptor 1 (CMKLR1). A second chemerin receptor, G protein-coupled receptor 1 (GPR1) in mammals, binds chemerin with an affinity similar to CMKLR1; however, the function of GPR1 in mammals is essentially unknown. Herein, we report that expression of murine Gpr1 mRNA is high in brown adipose tissue and white adipose tissue (WAT) and skeletal muscle. In contrast to chemerin (Rarres2) and Cmklr1, Gpr1 expression predominates in the non-adipocyte stromal vascular fraction of WAT. Heterozygous and homozygous Gpr1-knockout mice fed on a high-fat diet developed more severe glucose intolerance than WT mice despite having no difference in body weight, adiposity, or energy expenditure. Moreover, mice lacking Gpr1 exhibited reduced glucose-stimulated insulin levels and elevated glucose levels in a pyruvate tolerance test. This study is the first, to our knowledge, to report the effects of Gpr1 deficiency on adiposity, energy balance, and glucose homeostasis in vivo. Moreover, these novel results demonstrate that GPR 1 is an active chemerin receptor that contributes to the regulation of glucose homeostasis during obesity.
\end{abstract}

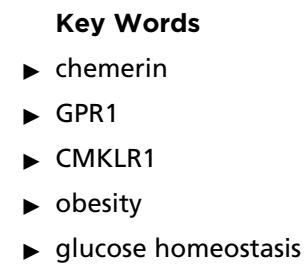

Journal of Endocrinology (2014) 222, 201-215

\section{Introduction}

Chemerin, also known as retinoic acid receptor responder (tazarotene-induced) 2, is a hormone-like protein that is secreted by the liver and white adipose tissue (WAT) as well as at localized sites of inflammation (Goralski et al. 2007, Albanesi et al. 2009). Circulating chemerin levels increase with chronic inflammatory diseases and are significantly elevated with obesity. These increases are positively correlated with deleterious elevations in levels of proinflammatory adipokines, inflammatory markers, and insulin resistance, and increased risk of the development and severity of comorbidities such as metabolic syndrome and type 2 diabetes (Lehrke et al. 2009, Tan et al. 2009, Sell et al. 2010).

http://joe.endocrinology-journals.org DOI: 10.1530/JOE-14-0069
() 2014 Society for Endocrinology Printed in Great Britain
A growing number of in vitro and in vivo studies support chemerin as a regulator of immune function, adipose tissue function, and glucose homeostasis (Rourke et al. 2013). In the immune system, chemerin acts as a potent chemoattractant for macrophages, immature dendritic cells, and natural killer cells (Wittamer et al. 2003, Vermi et al. 2005, Parolini et al. 2007, Hart \& Greaves 2010). In adipocytes, chemerin and its cognate $G$ proteincoupled receptor (GPCR) chemokine-like receptor 1 (CMKLR1) promote adipocyte differentiation and influence metabolic function of mature adipocytes (Goralski et al. 2007, Muruganandan et al. 2011). Chemerin secretion from WAT is increased in obesity. This increase

Published by Bioscientifica Ltd 
is often but not always associated with an increase in chemerin (Rarres2) mRNA expression in WAT and/or altered Cmklr1 expression in a variety of peripheral tissues including skeletal muscle, liver, and WAT. These changes are thought to contribute to the development and/or pathogenesis of obesity; however, the nature of this relationship remains unclear. It is widely accepted that chemerin and CMKLR1 also play a role in glucose homeostasis; however, investigations into the exact nature of this role have provided conflicting results. Notably, Cmklr1 knockout (KO) mice have been shown to exhibit both normal and glucose-intolerant phenotypes; while, chemerin (Rarres2) KO mice develop impaired insulin secretion and glucose intolerance (Takahashi et al. 2011, Ernst et al. 2012, Rouger et al. 2013, Gruben et al. 2014). In contrast, several models of obese mice demonstrate exacerbated glucose intolerance with chemerin treatment (Becker et al. 2010, Ernst et al. 2010). Moreover, in vitro studies using 3T3-L1 adipocytes show both increased and decreased glucose uptake with chemerin treatment (Takahashi et al. 2008, Kralisch et al. 2009). Collectively, these studies illustrate the complexity of chemerin function and indicate that the nature of chemerin function in glucose homeostasis is both context-specific and highly regulated.

To date, the majority of known chemerin functions have been attributed to the activation of CMKLR1 in target cells and tissues. However, this fails to fully explain the complexity of observed chemerin activities in obesity and glucose homeostasis. In 2008, GPR1, the closest phylogenetic relative of CMKLR1 in the family of chemoattractant receptors (Marchese et al. 1994a, Huang et al. 2010), was determined to both bind and become activated by recombinant chemerin (Barnea et al. 2008). To date, chemerin is the only known ligand for GPR1. As such, GPR1 may contribute to chemerin function; however, the role of GPR1 as a chemerin receptor has not been explored. Consequently, aside from a few reports implicating GPR1 as a low-efficiency HIV co-receptor (Marchese et al. 1994a, Farzan et al. 1997, Edinger et al. 1998, Huang et al. 2010), the function of this highly conserved receptor in mammals remains unknown.

The objectives of this study were to characterize in vivo tissue Gpr1 expression and the metabolic effects of Gpr1 loss. Herein, we demonstrate that Gpr1 is expressed within metabolically active tissues and report for the first time, to our knowledge, the generation and metabolic phenotyping of the Gpr1-null mouse. Moreover, we report the novel finding that GPR1 plays a functional role in glucose homeostasis during obesity.

\section{Materials and methods}

\section{Chemerin receptor Tango assay}

Chemerin receptor activity was estimated using a $\beta$-arrestin-based Tango assay system with both human CMKLR1- and GPR1-transcriptional transactivator fusion proteins and recombinant human chemerin 157 (R\&D Systems, Minneapolis, ME, USA) in passage 5-20 HTLA cells as described previously (Parlee et al. 2010).

\section{Animals}

All protocols were conducted in accordance with the Canadian Council on Animal Care guidelines and approved by the Dalhousie University Committee on Laboratory Animals. Animals were maintained at $25^{\circ} \mathrm{C}$ on a $12 \mathrm{~h}$ light: $12 \mathrm{~h}$ darkness cycle with access to food and water and allowed to feed ad libitum. WT Gpr1 ${ }^{+/+}$, heterozygous $\mathrm{Gpr}^{+/-}$(HET), and $\mathrm{KO} \mathrm{Gpr}^{-/-}$male littermates used in these studies were generated as described in Fig. 1 by HET $\times$ HET mating. Two groups of Gpr1 WT, HET, and KO mice (six to eight animals per genotype per group) were individually housed at 5 weeks of age. At 7 weeks of age, one group was placed on a low-fat diet (LFD) and the other on a high-fat diet (HFD) composed of 10 and $60 \% \mathrm{kcal}$ from fat respectively (Research Diets, New Brunswick, NJ, USA; D12450B and D12492). Animals were killed using an overdose $(90 \mathrm{mg} / \mathrm{kg})$ of pentobarbital sodium injected intraperitoneally followed by exsanguination.

\section{Tissue and RNA isolation}

Tissues were collected, snap frozen in liquid nitrogen, and stored at $-80^{\circ} \mathrm{C}$ until processed. RNA was isolated using TRIzol (Life Technologies) or Direct-zol 96-RNA (Zymo Research, Irvine, CA, USA) according to the manufacturer's protocol. Adipocyte and stromal vascular fractions (SVF) were isolated from epididymal WAT as described previously (Hausman et al. 2008).

\section{RT-PCR and quantitative real-time PCR}

RT was used to generate cDNA from $0.5 \mu \mathrm{g}$ isolated RNA. Exon-spanning quantitative real-time PCR (qPCR) primers were designed using the Primer3 algorithm (Table 1). Gene expression was measured using the Brilliant III ultrafast qPCR master mix (Agilent, Mississauga, ON, Canada) or Roche FastStart SYBR Green Master (Roche) according to the manufacturer's instructions. Relative

Published by Bioscientifica Ltd 
Table 1 Quantitative real-time PCR ( $q P C R$ ) and genotyping primers

\begin{tabular}{|c|c|c|}
\hline & Sequences $\left(5^{\prime}-3^{\prime}\right)$ & $\begin{array}{l}\text { Accession } \\
\text { numbers }\end{array}$ \\
\hline \multicolumn{3}{|l|}{ qPCR primers } \\
\hline Chemerin (Rarres2) & $\begin{array}{l}\text { Fw: TACAGGTGGCTCTGGAGGAGTTC } \\
\text { Rv: CTTCTCCCGTTTGGTTTGATTG }\end{array}$ & NM_027852 \\
\hline Cmklr1 & $\begin{array}{l}\text { Fw: GCTTTGGCTACTTTGTGGACTT } \\
\text { Rv: CAGTGTTCACGGTCTTCTTCATCTTG }\end{array}$ & NM_008153 \\
\hline Gpr1 & $\begin{array}{l}\text { Fw: GTCTCCCAGCTTCCCCGCTG } \\
\text { Rv: CAAGCTGTCGTGGTGTTTGA }\end{array}$ & NM_146250 \\
\hline Glut4 & $\begin{array}{l}\text { Fw: ACTCTTGCCACACAGGCTCT } \\
\text { Rv: AATGGAGACTGATGCGCTCT }\end{array}$ & NM_009204 \\
\hline Myh1 & $\begin{array}{l}\text { Fw: CTTCAACCACCACATGTTCG } \\
\text { Rv: AGGTTTGGGCTTTTGGAAGT }\end{array}$ & NM_030679 \\
\hline $\operatorname{Tnf} \alpha$ & $\begin{array}{l}\text { Fw: CCCTCACACTCAGATCATCTTCT } \\
\text { Rv: GCTACGACGTGGGCTACAG }\end{array}$ & NM_013693 \\
\hline $1 / 6$ & $\begin{array}{l}\text { Fw: TAGTCCTTCCTACCCCAATTTCC } \\
\text { Rv: TTGGTCCTTAGCCACTCCTTC }\end{array}$ & NM_031168 \\
\hline Lep & $\begin{array}{l}\text { Fw: GAGACCCCTGTGTCGGTTC } \\
\text { Rv: CTGCGTGTGTGAAATGTCATTG }\end{array}$ & NM_008493 \\
\hline Insr & $\begin{array}{l}\text { Fw: CCTGTACCCTGGAGAGGTGT } \\
\text { Rv: CGGATGACTGTGAGATTTGG }\end{array}$ & NM_010568 \\
\hline$\beta G e o$ & $\begin{array}{l}\text { Fw: GTCTCCCAGCTTCCCCGCTG } \\
\text { Rv: ACAGTATCGGCCTCAGGAA }\end{array}$ & $\begin{array}{l}\text { NM_146250 } \\
\text { EU676801 }\end{array}$ \\
\hline Ppia & $\begin{array}{l}\text { Fw: GAGCTGTTTGCAGACAAAGTTC } \\
\text { Rv: CCCTGGCACATGAATCCTGG }\end{array}$ & NM_008907 \\
\hline \multicolumn{3}{|c|}{ Gpr1 genotyping primers } \\
\hline Endogenous (Ef) & Fw: CGTGGAGCATATGAAACTCAAGG & NM_146250 \\
\hline Endogenous (Er) & Rv: TGTTCTCTTCTTCCACCTTGTGG & NM_146250 \\
\hline Targeted (Tr) & Rv: AAATGGCGTTACTTAAGCTAGCTTGC & EU676801 \\
\hline
\end{tabular}

gene expression was calculated using the $\Delta \Delta C t$ method (Livak \& Schmittgen 2001) with cyclophilin A (Cyca (Ppia)) as the reference gene.

\section{Body composition}

Total, fat, and lean masses were quantified in anesthetized mice as described previously using a GE Lunar Piximus2 bone densitometer (Ernst et al. 2012). Organ weights were measured from excised tissues.

\section{Activity and indirect calorimetry}

Measurement of activity and food consumption, and indirect calorimetry were performed in Panlab Physiocages (Panlab Harvard Apparatus, Barcelona, Spain). Data were collected for $24 \mathrm{~h}$ following $24 \mathrm{~h}$ acclimatization and analyzed using the Metabolism Software (Panlab Harvard Apparatus).

\section{Glucose homeostasis}

The glucose tolerance test (GTT) and insulin sensitivity test (IST) were carried out on conscious WT, HET, and
KO mice at 6-7 weeks of age and following 7, 13, 19, and 23 (GTT) or 6, 12, 18, and 22 (IST) weeks of feeding with either a LFD or a HFD as described previously (Ernst et al. 2010). Tissue glucose uptake during GTT was determined as described previously (Ernst et al. 2010).

\section{Blood chemistry}

Blood, collected from the saphenous veins of conscious mice, was clotted for $2 \mathrm{~h}$ for serum collection. ELISAs were performed according to the manufacturer's instructions to determine serum levels of total insulin (Crystal Chem, Downers Grove, IL, USA; cat no. 90080) and chemerin (R\&D Systems; DY2325) from undiluted and one in 1000 serum dilution respectively.

\section{Results}

\section{GPR1 is an active chemerin receptor}

We used a Tango bioassay (Barnea et al. 2008) to measure CMKLR1 or GPR1 activation in HTLA cells following treatment with increasing doses of chemerin (Fig. 2a).

Published by Bioscientifica Ltd 
Chemerin activated CMKLR1 and GPR1 with a similar efficacy, reaching a maximal response (Emax) of $265.3 \pm$ 182.2- and 185.6 \pm 26.5 -fold change above vehicle respectively. Moreover, chemerin activated GPR1 with a significantly higher potency $\left(\mathrm{EC}_{50}, 18.2 \pm 2.9 \mathrm{nM}\right)$ than CMKLR1 ( $\left.\mathrm{EC}_{50}, 54.6 \pm 30.7 \mathrm{nM}\right)$, demonstrating not only that chemerin activates GPR1, but also that GPR1 is a highly sensitive chemerin receptor. (a) Endogenous

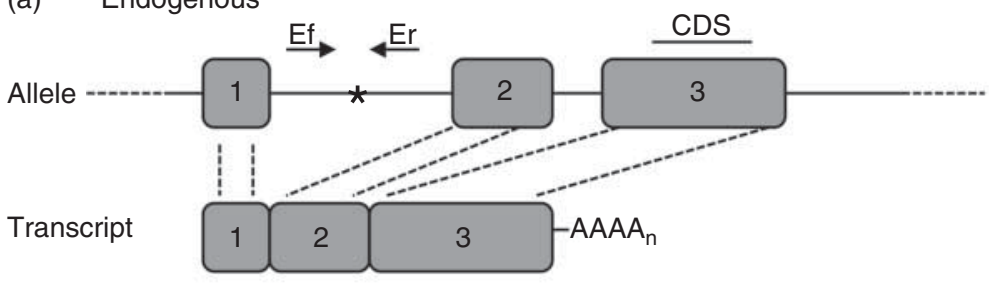

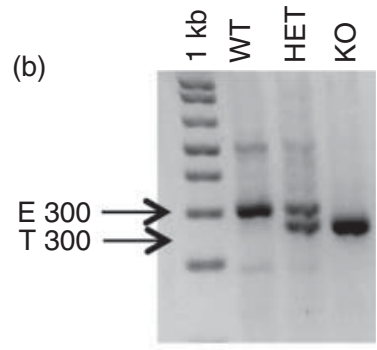

Targeted

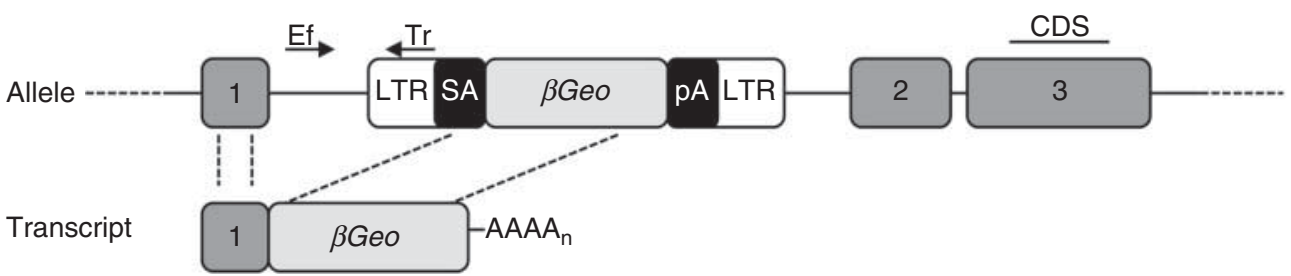

-WT $\square \mathrm{KO}$

(c)

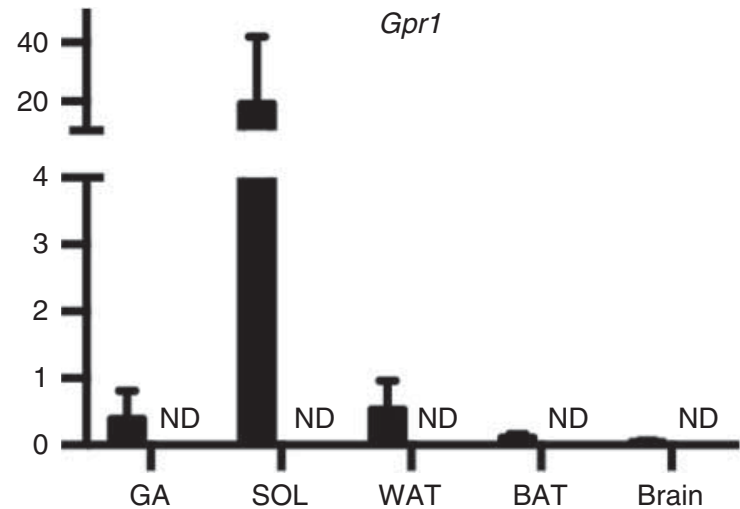

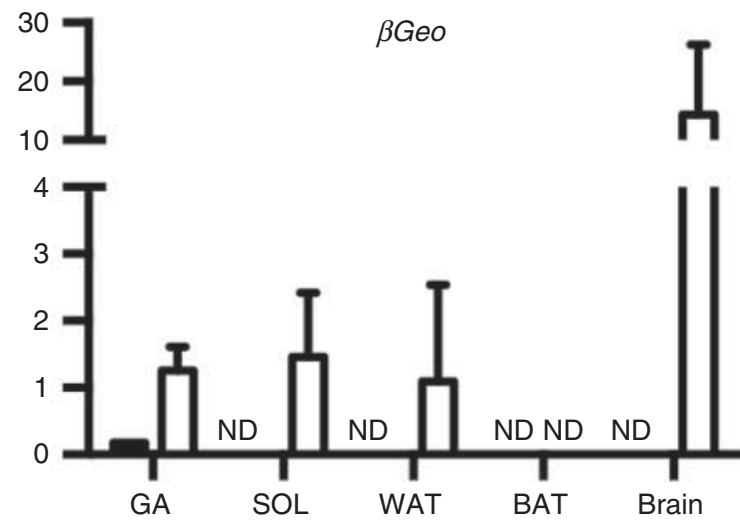

\section{Figure 1}

Gpr1-null mouse model generation and confirmation of gene deletion. Heterozygous $\mathrm{Gpr}^{+/-}$(HET) mice on a C57BL/6 background were generated at the Texas Institute of Genomic Medicine using a retroviral gene trap strategy for the targeted disruption of the Gpr1 allele. Schematic representation of the endogenous WT Gpr1 allele or the targeted allele containing the viral long terminal repeats (LTRS) used for target sequence insertion, the splice acceptor (SA) required for alternative splicing of the targeted transcript, a $\beta$-galactosidase neomycin resistance fusion gene $(\beta G e o)$, and a polyadenylation sequence (pA) (a). Transcripts produced from the endogenous allele contain all three Gpr1 exons (represented by numbered gray boxes), including exon 3, which contains the complete Gpr1 coding sequence (CDS). As a consequence of the SA in the targeted allele, the target mRNA transcript contains only exon $1, \beta G e o$, and a polyadenylated tale $\left(\mathrm{AAAA}_{n}\right)$. Confirmation of targeted allele generation and genotyping (c) 2014 Society for Endocrinology Printed in Great Britain was performed using a PCR assay. Arrows indicate the position of Gpr1 genotyping primers: a forward primer (Ef) located $5^{\prime}$ to the insertion site together with a combination of reverse primers located in the endogenous (Er) sequence $3^{\prime}$ to the insertion site and the LTRs of the targeted (Tr) sequence. To determine the genotype of mice from HET $\times$ HET breeding pairs, PCR products generated using ear-clip DNA and the genotyping primers were resolved by DNA gel electrophoresis with size approximation using a $1-k b+$ ladder. The arrow indicates endogenous $(E)$ and transgenic $(T)$ product sizes (b). Loss of Gpr 1 and gain of $\beta G e o$ mRNA transcript expression in knockout (KO) mice were confirmed using quantitative real-time PCR (qPCR) in gastrocnemius (GA), soleus (SOL), epididymal white adipose tissue (WAT), brown adipose tissue (BAT), and brain of WT and Gpr1 KO mice to show loss (not detected (ND)) of Gpr 1 and gain of $\beta$ Geo mRNA in WT and KO mice respectively (c). Results are expressed relative to $\mathrm{GA}, n=3-4$. 


\section{Gpr1 mRNA is expressed in WAT and skeletal muscle}

To compare the relative abundance of Cmklr1 and Gpr1, the mRNA levels were measured in a panel of C57BL/6 mouse tissues (Fig. 2b). Consistent with previous results (Goralski et al. 2007), Cmklr1 expression was predominant in WAT and the lung, but it was also present at lower levels in heart, liver, kidney, spleen, thymus, skeletal muscle, brain, and brown adipose tissue (BAT). Similar to Cmklr1, Gpr1 expression was lowest in heart, lung, liver, kidney, spleen, and thymus and was highest in the WAT. Gpr1 was also abundant in other metabolically active tissues including skeletal muscle, brain, and BAT. Further characterization of individual hind limb muscles demonstrated that Cmklr1 and Gpr1 mRNA expression was two- to threefold higher in the soleus muscle compared with the gastrocnemius (GA) and tibialis anterior muscles. This expression pattern was inversely related to the relative expression of myosin heavy polypeptide 1 (Myh1), which marks the difference in fiber type found in these muscles. Chemerin (Rarres2) mRNA was also expressed in all three muscles, following a similar pattern to glucose transporter 4 (Glut4 (Slc2a4)), the primary
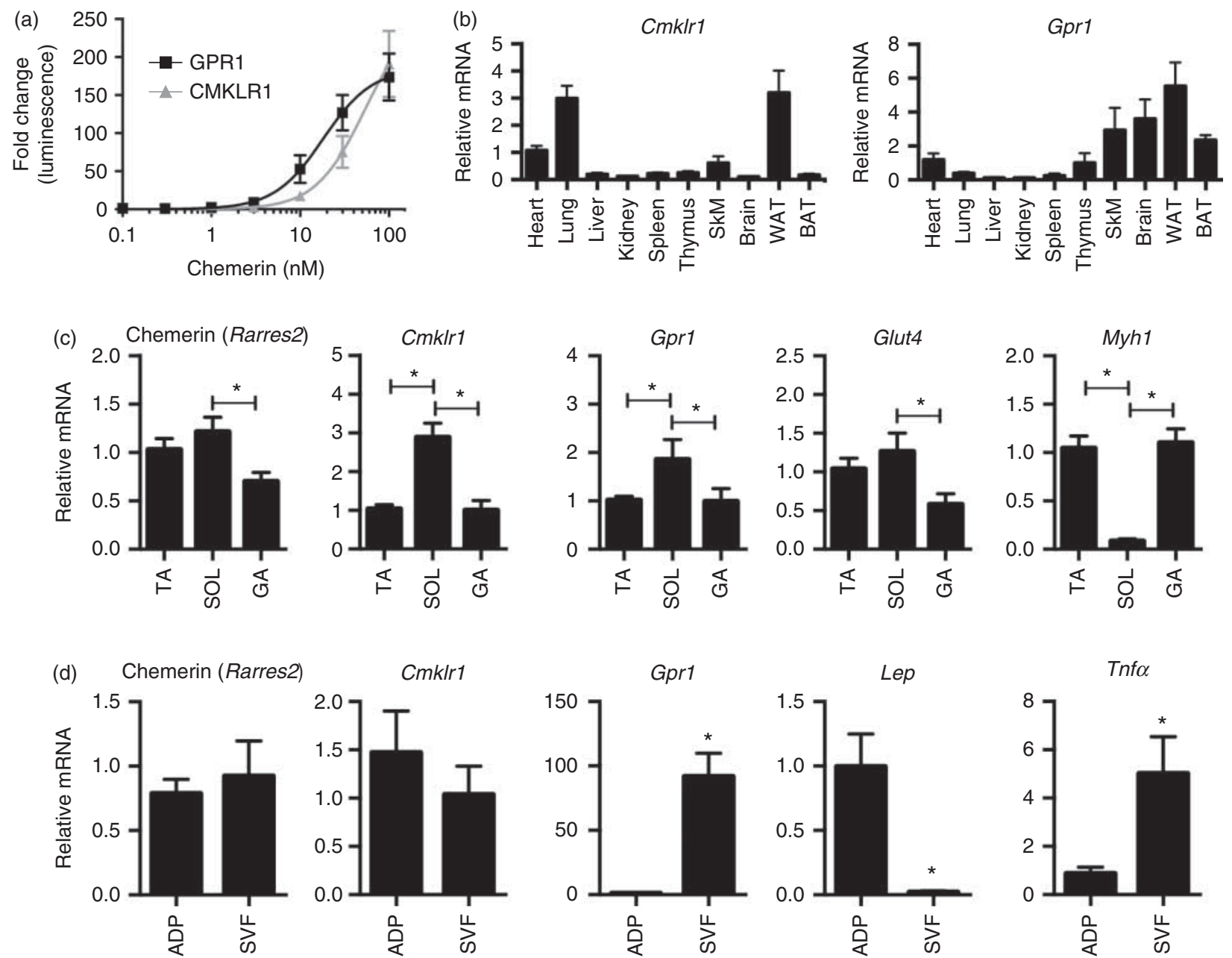

Figure 2

GPR 1 is an active chemerin receptor and is expressed in metabolically active tissues. GPR1- or CMKLR1-tTA fusion receptors were expressed in HTLA cells to assess receptor activation following treatment with increasing doses of recombinant human chemerin. The resulting luminescent signal was expressed as the fold-change in luminescence relative to $0 \mathrm{nM}$ chemerin treatment, $n=13-28$ (a). Gpr1 and CmkIr1 mRNA expression was measured by qPCR analysis in the indicated tissues (SkM, skeletal muscle) from 8-12-week-old mice and expressed relative to heart, $n=6$ (b). Gpr1, Cmklr1, chemerin (Rarres2), glucose transporter 4 (Glut4), and myosin heavy polypeptide 1 (Myh1) mRNA levels were measured by qPCR analysis in isolated tibialis anterior (TA), soleus (SOL), and gastrocnemius (GA) muscles from male and female mice and expressed relative to TA, $n=5-7$ (c). Gpr1, Cmklr1, chemerin (Rarres2), Lep, and Tnf $\alpha$ mRNA expression were determined by qPCR analysis in adipocyte (ADP) and stromal vascular fraction (SVF) cells isolated from WAT, $n=5-6$. Results are expressed relative to ADP (d). All tissues were collected from 10-12-week-old WT mice. One-way ANOVA (c) and $t$-test (d), ${ }^{\star} P<0.05$ as indicated. http://joe.endocrinology-journals.org DOI: 10.1530/JOE-14-0069
(C) 2014 Society for Endocrinology Printed in Great Britain 
transporter for insulin-stimulated glucose uptake in skeletal muscles.

WAT is comprised of adipocytes, which store excess energy as lipid, and a heterogeneous population of stromal vascular cells including leukocytes, adipose stem cells, endothelial cells, smooth muscle cells, and pericytes, which contribute to normal WAT maintenance and function. Consistent with our previous results (Goralski et al. 2007), chemerin (Rarres2) and Cmklr1 mRNA were abundant in adipocytes and SVF cells (Fig. 2d). In contrast, Gpr1 mRNA expression was more than 90-fold higher in SVF than in adipocytes. Differential expression of the adipocyte (leptin (Lep)) and SVF (tumor necrosis factor alpha (Tnfo (Tnf))) markers confirmed effective fraction separation. Based on this initial characterization of Gpr1 expression and the established function of chemerin in metabolism, we proposed that GPR1 plays a role in glucose homeostasis and WAT differentiation or function.

\section{Gpr1 loss does not alter weight gain on a HFD}

To investigate the in vivo function of GPR1, mice lacking Gpr1 expression in all tissues were generated (Fig. 1). Newborn and adult Gpr1 HET and KO mice were grossly indistinguishable from WT littermates when monitored from birth until 40 weeks of age. HET breeding crosses generated offspring exhibiting the expected Mendelian distribution and frequency of WT and KO alleles and no sexual bias (data not shown). To determine whether GPR1 contributes to metabolic function, Gpr1 WT, HET, and KO mice were placed on either a LFD or a HFD for 24 weeks. Gpr1 mRNA levels were unchanged in WAT and GA muscles and were significantly reduced in SOL of mice that had consumed a HFD for 24 weeks (Fig. 3a). As changes in either chemerin or CMKLR1 levels contribute to altered energy and glucose homeostasis, total circulating chemerin as well as Cmklr1 and chemerin (Rarres2) mRNA expression was measured using ELISA and qPCR respectively (Fig. 3). Consistent with results described in previous reports (Bozaoglu et al. 2007, Ernst et al. 2010, Chakaroun et al. 2012), serum chemerin concentration increased by more than twofold following 24 weeks of feeding with a HFD compared with LFD but did not differ with respect to genotype on either diet (Fig. 3b). Similarly, Gpr1 loss did not result in altered chemerin (Fig. 3c) expression in the liver, WAT, or soleus muscle in mice fed on either the LFD or HFD. However, chemerin (Rarres2) mRNA levels were significantly reduced in both Gpr1 HET and KO GA of HFD-fed mice. Cmklr1 expression was reduced in the livers of KO mice fed on a HFD and soleus muscles of HET mice (a)

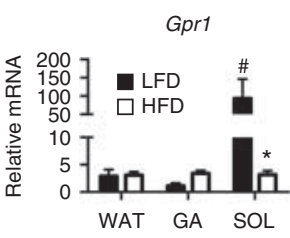

(c)
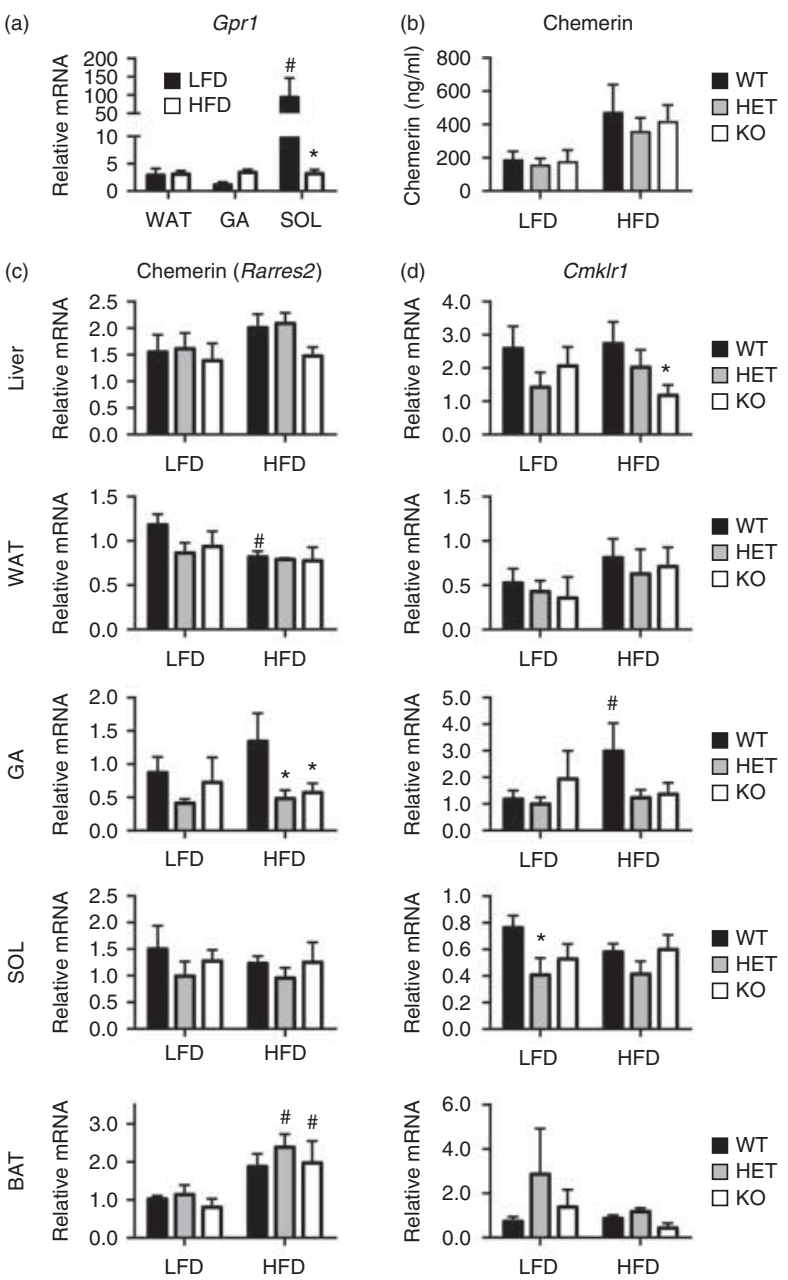

(e)

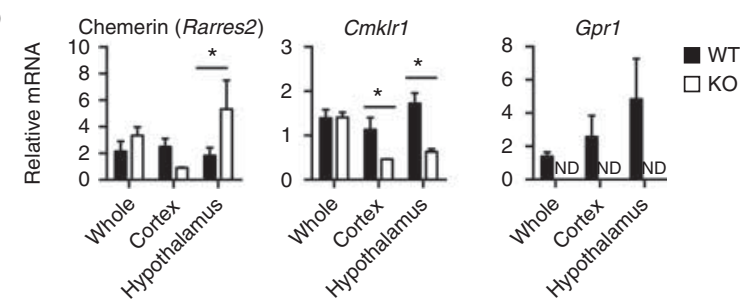

Figure 3

Chemerin (Rarres2) and Cmklr1 expression with Gpr1 loss. Gpr1 mRNA expression was measured in epididymal white adipose tissue (WAT), gastrocnemius (GA), and soleus (SOL) muscles from WT mice (a), $n=4-7$. Results are expressed relative to low-fat diet (LFD) WAT, $*<0.05$ vs LFD and ${ }^{\#} P<0.05$ vs WT WAT and GA. Total circulating chemerin concentration in serum samples was determined using a mouse chemerin ELISA, $n=5-8(b)$. Chemerin (Rarres2) (c) and CmkIr1 (d) mRNA expression were measured using qPCR analysis in the liver, WAT, GA and SOL muscles, and brown adipose tissue (BAT), $n=5-8$. Results are expressed relative to LFD WT mice. All samples were from Gpr1 WT, heterozygous (HET), or homozygous knockout (KO) mice following 24 weeks of feeding with either a LFD or a high-fat diet (HFD) as indicated. One-way ANOVA, ${ }^{\star} P<0.05$ vs WT within diet or ${ }^{\#} P<0.05$ vs LFD. Chemerin (Rarres2), Cmklr1, and Gpr1 mRNA expression were measured in the whole brain, cortex, and hypothalamus isolated from 30-week-old WT and KO mice consuming a LFD (e), $n=4$. Results are expressed relative to WT whole brain. Two-way ANOVA, $* P<0.05$ vs WT within tissue. 

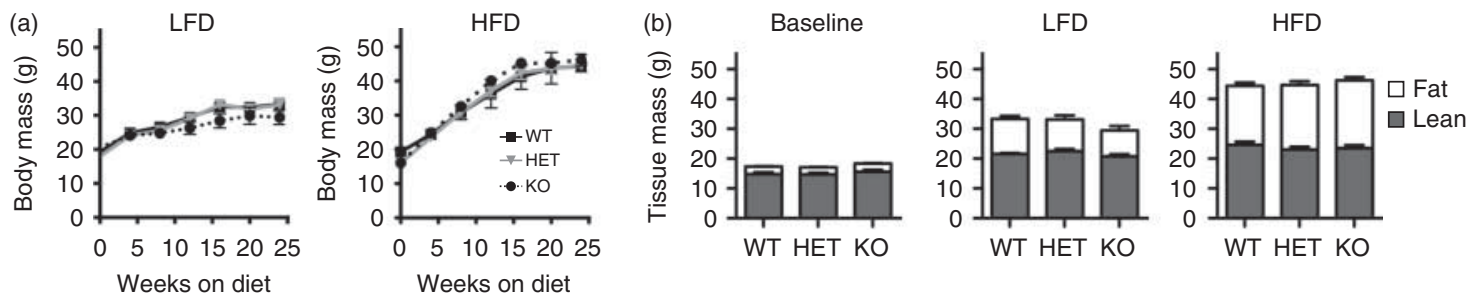

\section{Figure 4}

Gpr1 knockout (KO) mice have normal body weight and fat mass. Total body mass was measured for 24 weeks in Gpr1 WT, heterozygous (HET), or homozygous KO mice placed on either a low-fat diet (LFD) or a high-fat diet (HFD) at 7 weeks of age (a). Dual-energy X-ray absorptiometry was used to calculate the mass of total fat (white bars) and lean (black bars)

fed on a LFD and was unchanged with either diet in WAT and GA (Fig. 3d). In the brain, Gpr1 loss resulted in increased chemerin (Rarres2) mRNA expression in the hypothalamus, as well as decreased cortex and hypothalamic Cmklr1 expression.

To determine whether GPR1 plays a role in growth and WAT development, we assessed body composition by dual-energy X-ray absorptiometry (Fig. 4). Mice consuming a HFD had significantly higher fat mass and accelerated body weight gain (Fig. 4a and b) compared with those fed on a LFD; however, no differences were observed in body, fat, or lean mass between the genotypes in mice fed on either diet. Measurement of major organ mass following 24 weeks of feeding with either a LFD or a HFD revealed a significant increase in GA muscle, soleus muscle, perirenal WAT, and subcutaneous WAT tissue mass (Table 2) in mice consuming a HFD irrespective of the genotype. Similarly, liver and spleen mass were significantly elevated with the HFD in WT and KO mice, while pancreas and BAT mass were only elevated in tissues at 6 weeks of age (baseline pooled LFD and HFD before diet initiation, $n=10-15)$ and following 24 weeks of feeding with either a LFD or a HFD $(n=6-8)(\mathrm{b})$. One-way (b) repeated measures (a) ANOVA, $* P<0.05$ vs WT within diet.

HFD-fed WT and KO mice respectively. No significant differences were observed between the genotypes within any particular tissue. Consistent with the absence of genotype-driven differences in WAT mass, adipocyte differentiation of mesenchymal stem cells isolated from HET and $\mathrm{KO}$ mice was indistinguishable from that of WT mice (data not shown).

Given the expression of Gpr1 in the metabolically active tissues, skeletal muscle, WAT, and brain, we assessed the effects of Gpr1 loss on metabolic homeostasis by measuring food consumption, activity, and energy expenditure (Fig. 5) in metabolic cages. For all genotypes, HFDfed mice were significantly more active than those fed on a LFD during the dark cycle (Fig. 5a). Energy expenditure was similar for all genotypes (Fig. 5b). Gpr1 WT, HET, and $\mathrm{KO}$ mice had similar food consumption in total and during the periods of light and darkness on a LFD (Fig. 5c). WT mice consuming a HFD had comparable total calorie consumption to LFD counterparts. In contrast, Gpr1 KO and HET mice consumed significantly fewer calories

Table 2 Body and organ weights of Gpr1 WT, HET and KO littermates fed on a LFD or a HFD for 24 weeks. Values are expressed as mean \pm S.E.M., $n=6-9$

\begin{tabular}{|c|c|c|c|c|c|c|}
\hline & \multicolumn{3}{|c|}{ LFD $(g)$} & \multicolumn{3}{|c|}{ HFD (g) } \\
\hline & WT & HET & KO & WT & HET & KO \\
\hline Whole body & $34.160 \pm 1.419$ & $36.520 \pm 2.009$ & $32.440 \pm 2.837$ & $45.230 \pm 3.093^{*}$ & $43.57 \pm 1.503^{*}$ & $47.620 \pm 1.782 *$ \\
\hline Liver & $1.723 \pm 0.154$ & $1.772 \pm 0.152$ & $1.653 \pm 0.242$ & $2.625 \pm 0.307^{*}$ & $2.102 \pm 0.277$ & $2.617 \pm 0.237 *$ \\
\hline $\mathrm{GA}$ & $0.233 \pm 0.029$ & $0.246 \pm 0.024$ & $0.212 \pm 0.034$ & $0.343 \pm 0.016 *$ & $0.331 \pm 0.015^{*}$ & $0.366 \pm 0.011 *$ \\
\hline Soleus & $0.020 \pm 0.004$ & $0.021 \pm 0.004$ & $0.020 \pm 0.004$ & $0.033 \pm 0.005^{*}$ & $0.030 \pm 0.002 *$ & $0.035 \pm 0.002 *$ \\
\hline Pancreas & $0.251 \pm 0.023$ & $0.300 \pm 0.028$ & $0.313 \pm 0.035$ & $0.412 \pm 0.061$ * & $0.399 \pm 0.054$ & $0.336 \pm 0.049$ \\
\hline Spleen & $0.093 \pm 0.006$ & $0.086 \pm 0.004$ & $0.085 \pm 0.004$ & $0.137 \pm 0.017 *$ & $0.114 \pm 0.019$ & $0.118 \pm 0.010 *$ \\
\hline PR WAT & $0.798 \pm 0.099$ & $0.827 \pm 0.100$ & $0.571 \pm 0.134$ & $2.143 \pm 0.145^{\star}$ & $2.085 \pm 0.169 *$ & $2.473 \pm 0.215^{*}$ \\
\hline EP WAT & $1.863 \pm 0.160$ & $1.773 \pm 0.219$ & $1.218 \pm 0.412$ & $1.839 \pm 0.351$ & $1.874 \pm 0.239$ & $1.981 \pm 0.158$ \\
\hline SC WAT & $0.953 \pm 0.088$ & $1.040 \pm 0.154$ & $0.596 \pm 0.214$ & $2.128 \pm 0.140 *$ & $2.365 \pm 0.099 *$ & $2.448 \pm 0.163 *$ \\
\hline BAT & $0.314 \pm 0.029$ & $0.290 \pm 0.042$ & $0.270 \pm 0.057$ & $0.322 \pm 0.039$ & $0.309 \pm 0.026$ & $0.410 \pm 0.052$ * \\
\hline
\end{tabular}

${ }^{*} P<0.05$ vs LFD of the same genotype. WAT, white adipose tissue; BAT, brown adipose tissue; LFD, low-fat diet; HFD, high-fat diet; GA, gastrocnemius; $\mathrm{PR}$, perirenal; EP, epididymal; SC, subcutaneous.

http://joe.endocrinology-journals.org DOI: $10.1530 / J O E-14-0069$
C 2014 Society for Endocrinology Printed in Great Britain
Published by Bioscientifica Ltd. 
(a)

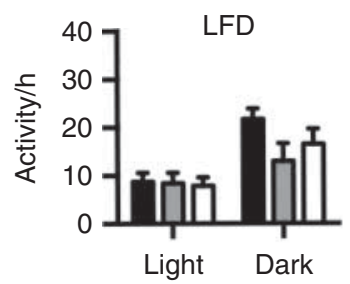

(b)

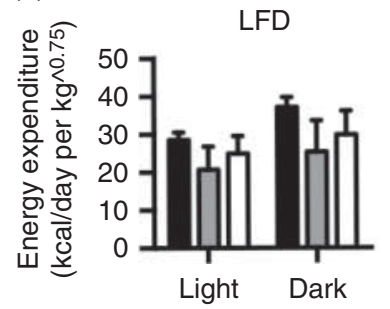

(c)
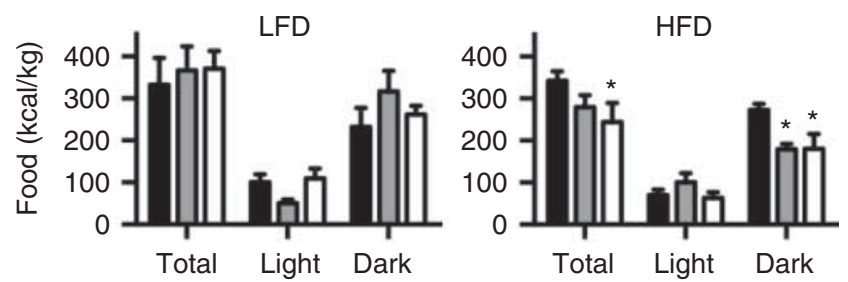

(d)

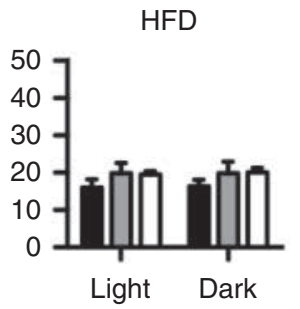

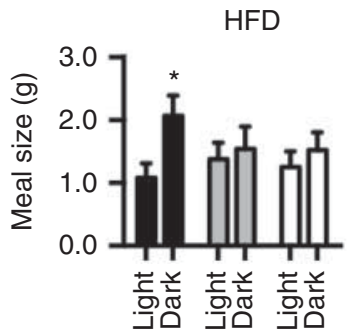

Figure 5

Gpr1 loss decreases feeding during periods of darkness but does not alter energy homeostasis. Metabolic cages were used to measure the locomotor activity (a), $\mathrm{VO}_{2}$ consumption/ $\mathrm{CO}_{2}$ generation for calculation of energy expenditure (b) and food consumption ( $c$ and d). Food consumption data are represented as total kcal consumed per kilogram body weight (c) and meals per hour or meal size (d). Metabolic cage measurements were taken

(30 and 20\% reduction respectively) than LFD-fed mice of the same genotype. Moreover, total HFD consumption was significantly lower in KO mice than in WT mice. Both Gpr1 HET and KO mice also consumed significantly less total food than WT mice during the period of darkness (Fig. 5c). While WT mice on a HFD had a significant increase in meal frequency and meal size during the period of darkness, this was not observed for Gpr1 HET or KO mice (Fig. 5d). Expression of the appetite-modulating hormones neuropeptide Y (NPY) and agouti-related peptide (AGRP) were unchanged in the hypothalamus with Gpr1 loss.

\section{Gpr1 deletion is associated with exacerbated glucose intolerance following prolonged HFD consumption}

To determine whether GPR1 plays a role in glucose homeostasis, fasting glucose, IST, GTT, and pyruvate tolerance test were conducted in Gpr1 WT, HET, and KO mice consuming either a LFD or a HFD (Fig. 6). No difference was detected between the genotypes with respect to fasting glucose before diet initiation or following up to 24 weeks of feeding with either a LFD or a HFD (Fig. 6a). Similarly, a single bolus of insulin produced a similar decline in blood glucose for Gpr1 WT, HET, and KO mice (Fig. 6b). Consistent with the development of insulin resistance, HFD consumption automatically every 2 min over a $24 \mathrm{~h}$ light/darkness cycle in WT, heterozygous (HET), or homozygous knockout (KO) mice following 24 weeks of feeding with either a low-fat diet (LFD) or a high-fat diet (HFD) as indicated. Two-way repeated measures ANOVA, ${ }^{*} P<0.05$ vs WT during the light period of the light:darkness cycle $(a, b$ and $c)$, or relative to WT during the period of light (d), $n=6-8$.

resulted in a smaller insulin-stimulated reduction in blood glucose than LFD; however, no overall genotypic effect was detected. Loss of Gpr1 had no significant effect on glucose tolerance at baseline or following 24 weeks of feeding with a LFD. WT mice became glucose intolerant following 24 weeks of feeding with a HFD, with peak blood glucose at $15 \mathrm{~min}$ following glucose injection approximately $20 \%$ higher than that observed in the LFD group. In contrast, both Gpr1 HET and KO mice exhibited significantly exacerbated glucose intolerance following 24 weeks of feeding with a HFD (Fig. 6c), compared with WT mice on the same diet. Glucose intolerance was more severe in $\mathrm{KO}$ mice, with an average approximate increase in blood glucose levels of $10 \%$ when compared with WT mice as early as 15 min following the glucose bolus. By 120 min following glucose administration, blood glucose levels of KO mice were $33 \%$ higher than those of WT mice. Intermediate between WT and $\mathrm{KO}$, blood glucose concentration increased more slowly in Gpr1 HET mice when compared with KO mice, becoming significantly elevated only at 90 and $120 \mathrm{~min}$ following the glucose injection and reaching an average of $40 \%$ increase above the levels for WT mice at 120 min. Upon administration of pyruvate administration for assessment of hepatic gluconeogenesis, blood glucose levels were significantly elevated for both Gpr1 WT and KO mice following 20 weeks of

Published by Bioscientifica Ltd. 
(a)
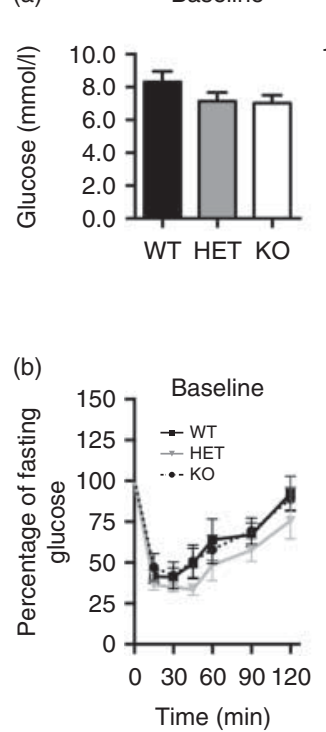

LFD
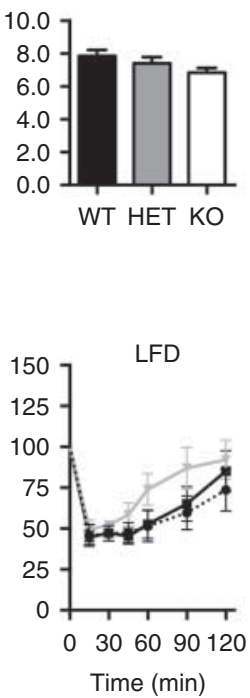

HFD
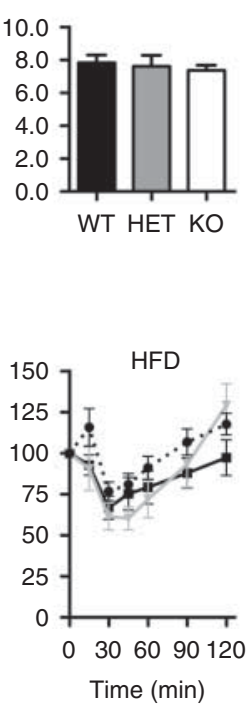
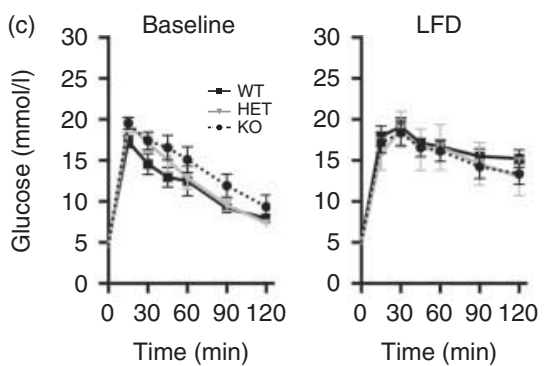

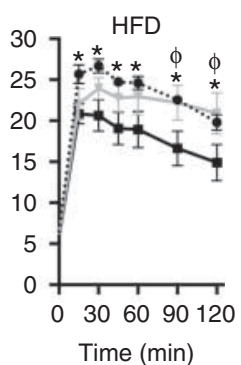

HFD
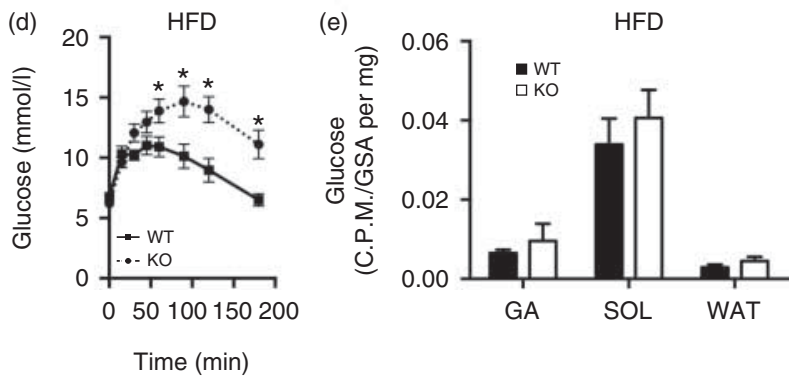

Figure 6

Gpr1 loss exacerbates glucose intolerance in mice fed on a high-fat diet (HFD) for 24 weeks. Blood glucose concentration was measured following a 5-6 h fast (a). Insulin sensitivity test (b), glucose tolerance test (c), and pyruvate tolerance test (d) were conducted following 18,6 , or $18 \mathrm{~h}$ fasting respectively. Blood glucose was monitored using a Freestyle Light glucometer with saphenous vein blood before (time 0 ) and 15, 45, 90, and $120 \mathrm{~min}$ after injection of human insulin $(0.75 \mathrm{U} / \mathrm{kg})(\mathrm{b})$, glucose $(2 \mathrm{mg} / \mathrm{g})$ (c), or pyruvate $(2 \mathrm{mg} / \mathrm{g})(\mathrm{d})$. Insulin and glucose testing were done on WT, heterozygous (HET), or homozygous knockout (KO) mice before diet

feeding with a HFD. Blood glucose levels in WT mice peaked after 30-45 min and declined back to baseline levels over the course of the experiment. While blood glucose levels increased and declined in $\mathrm{KO}$ mice at a rate similar to that in WT mice, peak blood glucose was delayed to 90 min with loss of Gpr1. Consistent with this delay, blood glucose levels were significantly higher in $\mathrm{KO}$ mice than in WT mice at 60, 90, 120, and 180 min (Fig. 6d). No differences in the mRNA levels for the gluconeogenic enzymes phosphoenolpyruvate carboxylase (Pepck (Pck1)) or glucose-6-phosphatase (G6pc) were observed between the genotypes (data not shown). To determine whether the elevations in blood glucose levels observed in the GTT and pyruvate tolerance test (PTT) were associated with a decrease in basal or insulin-stimulated glucose uptake, we performed tissue glucose uptake experiments in WT and Gpr1 KO mice after 20 weeks of feeding with a HFD (Fig. 6d). Glucose uptake in GA, soleus, and WAT was unchanged by loss of Gpr1 (Fig. 6e).

To determine whether the observed glucose intolerance on the HFD was a consequence of altered pancreatic insulin secretion, Gpr1 mRNA expression in

initiation (baseline pooled low-fat diet (LFD) and HFD, $n=9-14$ pooled LFD and HFD groups) or following 24 weeks of feeding with either a LFD or a HFD ( $n=6-8)$ as indicated. In vivo tissue glucose uptake was measured at $60 \mathrm{~min}$ following injection of tritiated 2-deoxyglucose (e). Glucose uptake and pyruvate testing were done in WT and KO mice following 20 weeks of feeding with a HFD. One-way ANOVA (a), one-way repeated measures ANOVA (b, c and d), ${ }^{*} P<0.05$ WT vs KO or ${ }^{\Phi} P<0.05$ WT vs HET at the indicated time points, two-way ANOVA (e).

the pancreas as well as pancreatic insulin content and circulating insulin levels was measured (Fig. 7). Gpr1 mRNA expression in the pancreas was similar to that in the brain, GA, and WAT and was significantly lower than that in soleus muscle (Fig. 7a). Total pancreatic insulin content was unchanged with Gpr1 loss in HFD-fed mice (Fig. 7b) and fasting serum insulin levels were similar between the genotypes in mice consuming the LFD. Consistent with the development of insulin resistance, fasting serum insulin levels were significantly elevated in WT mice consuming the HFD compared with LFD-fed mice. In contrast, Gpr1 KO mice exhibited more than $50 \%$ lower fasting serum insulin levels than WT mice fed on the HFD (Fig. 7c). Moreover, glucose-stimulated serum insulin levels (Fig. 7d) and area under the insulin curve (Fig. 7e) were lower in $\mathrm{KO}$ mice compared with WT and HET mice for both the LFD and HFD; however, this trend was significant only at the 45 min time point of the HFD.

Liver steatosis, adipocyte hypertrophy, and inflammation are common features of obesity, contributing to the development of glucose intolerance. Gpr1 WT, HET, 
(a) Gpr1

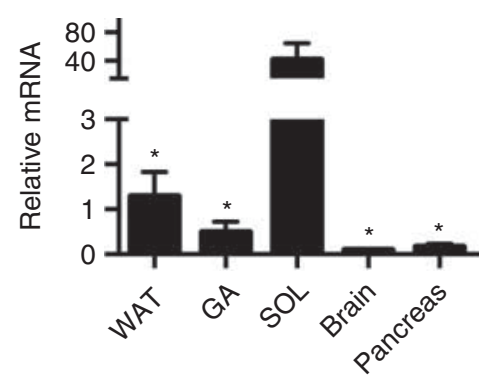

(c)

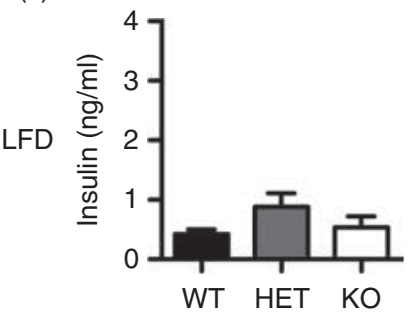

(d)

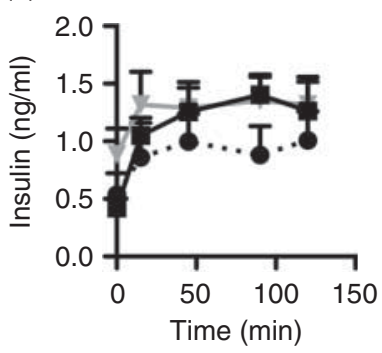

(e)
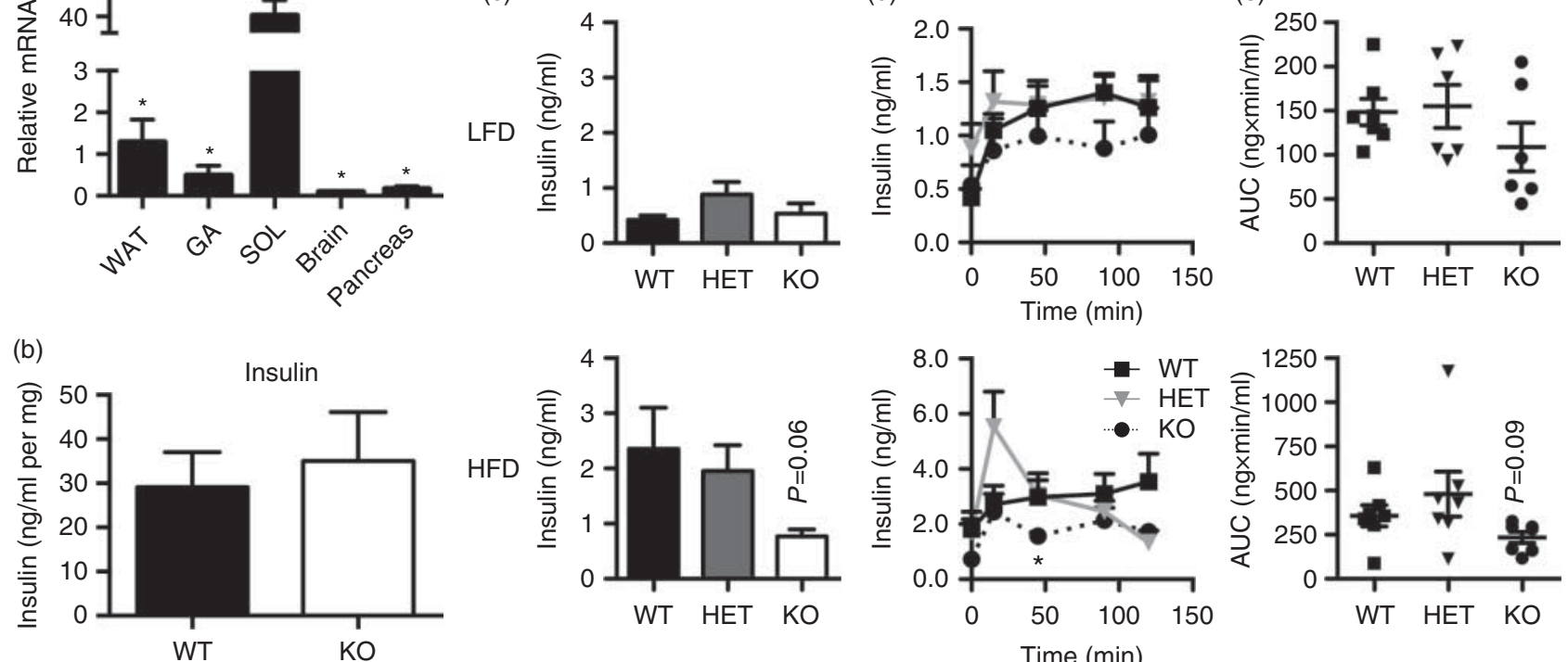

Figure 7

Insulin secretion is reduced in obese Gpr1 KO mice. Gpr1 mRNA expression was measured in epididymal white adipose tissue (WAT), gastrocnemius (GA) and soleus (SOL) muscles, brain, and pancreas from 30-week-old WT mice and expressed relative to WAT (a). One-way ANOVA, ${ }^{*} P 0.05$ vs SOL, $n=4$. Total pancreatic insulin was extracted from WT and KO mice using acid ethanol following 20 weeks of feeding with a HFD and quantified by

and $\mathrm{KO}$ mice fed on a LFD had minimal lipid deposition in the liver and all developed similar hepatic steatosis in response to the HFD (Fig. 8a and b). Although liver steatosis is commonly associated with inflammation, hepatic mRNA expression of the proinflammatory cytokines $T n f \alpha$ and interleukin 6 (Il6) did not reveal any differences in liver inflammation on either diet or with Gpr1 loss (Fig. 8c). Similarly, WAT histology demonstrated an increase in crown-like structures indicative of infiltrating macrophages and dead adipocytes (Cinti et al. 2005) with a HFD but did not display any gross morphological differences between the genotypes on either diet (Fig. 8d). Frequency analysis of adipocyte size showed that Gpr1 HET and KO mice had a similar distribution of adipocyte sizes to WT mice fed on both the LFD and the HFD (data not shown). There was no difference between the genotypes in $T n f \alpha$ or the macrophage marker macrophage antigen 1 (Mac1 (Mph1)) mRNA expression in WAT on either diet (Fig. 8e). Taken together, these data indicate that Gpr1 loss does not alter liver/WAT morphology or inflammation in lean or obese mice.

In peripheral tissues, insulin activation of the insulin receptor (INSR) promotes GLUT4-mediated glucose uptake and lowering of blood glucose levels. Insulin resistance
ELISA, $n=4-7$ (b). Serum insulin concentration during the glucose tolerance test was measured in the fasting state before (c) and 15, 45, 90, and 120 min after glucose injection using a mouse insulin ELISA. $* P<0.05$ vs WT, one-way (c and e) and repeated measures (d) ANOVA, $n=6-8$ (d). Area under the curve (AUC) for insulin was calculated using the Prism6 Software (La Jolla, CA, USA).

and impaired peripheral tissue glucose uptake are common features of obesity-associated glucose intolerance. Consistent with the development of insulin resistance, Glut4 mRNA expression in WAT was 50\% lower in mice fed on a HFD compared with mice consuming a LFD; however, compared with WT mice, Gpr1 HET and KO mice did not have altered Glut4 mRNA expression in any of the tissues examined on either diet (Fig. 9a). In contrast, while Insr mRNA expression showed no change with a HFD in the examined tissues and no difference with Gpr1 loss in WAT or soleus muscles, there was a significant decrease in Insr mRNA expression in the GA muscles of Gpr1 KO mice fed on a HFD (Fig. 9b).

\section{Discussion}

The goal of this study was to examine the contribution of GPR1 to the biological effects of chemerin by evaluating the phenotype of Gpr1 KO mice. We have shown that Gpr1 mRNA expression predominates in skeletal muscle and WAT, and is highest in the SVF of WAT. While Gpr1 KO mice consumed significantly less food, their total activity and energy expenditure were not different from those of WT mice. Consistent with this, Gpr1 KO mice had normal

Published by Bioscientifica Ltd 
(a)

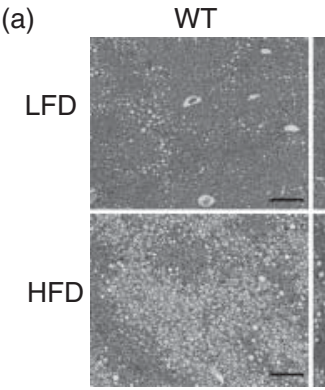

(b)

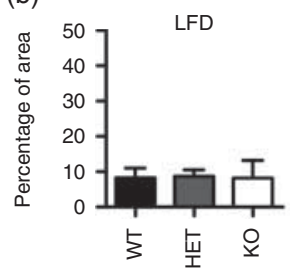

HET
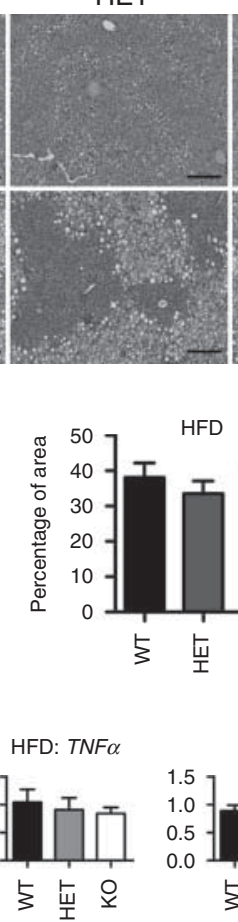

HFD

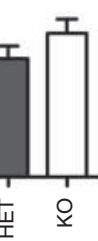

KO

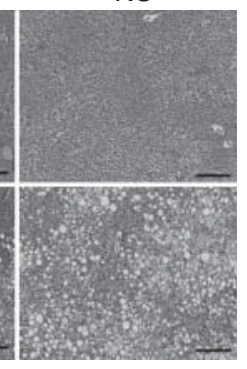

(e)

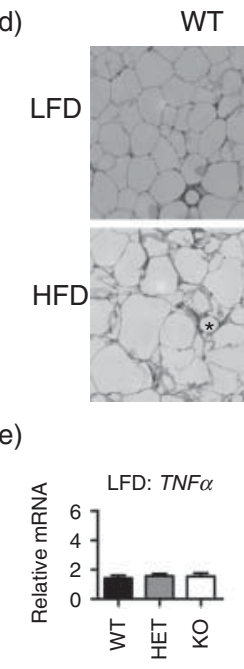

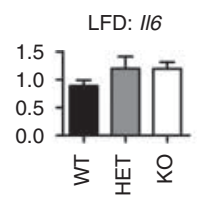

3 또

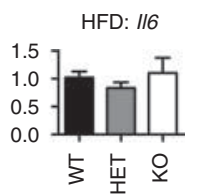

\section{Figure 8}

Gpr1 loss is not associated with altered liver steatosis or adipose tissue inflammation. Freshly isolated tissues from WT, heterozygous (HET), or homozygous knockout (KO) mice consuming either a low-fat diet (LFD) or a high-fat diet (HFD) for 24 weeks were fixed for $48 \mathrm{~h}$ (liver) or 2 weeks (WAT) in $10 \%$ neutral buffered formalin, washed twice for $24 \mathrm{~h}$ with $70 \%$ ethanol, and embedded in paraffin before sectioning $(4 \mu \mathrm{m})$ and hematoxylin and eosin staining. Representative images of liver (a) were used for quantification of $\%$ adipocyte area using the ImageJ Software

body weight, adipose development, and tissue inflammation. However, loss of Gpr1 resulted in exacerbation of HFD-induced glucose intolerance, elevated blood glucose following a pyruvate challenge, and reduced glucosestimulated circulating insulin in obese mice. As such, this study provides the first, to our knowledge, empirical evidence supporting a mammalian function for GPR1 as a modifier of glucose homeostasis during obesity.

The varied population of adipose stem cells and leukocytes within the SVF supports WAT differentiation and expansion and connects energy homeostasis with immunity and inflammation (Lolmede et al. 2011). Although Gpr1 mRNA has been reported previously in adipocytes (Regard et al. 2008), we report here for the first time, to our knowledge, that Gpr1 mRNA expression was markedly higher in the SVF than in adipocytes. As such, the relative importance of chemerin signaling through GPR1 may be greatest in the SVF where GPR1 may contribute to immune function and/or WAT
(National Institutes of Health, Bethesda, MD, USA), $n=6$ (b). Scale bars represent $200 \mu \mathrm{m}$. Liver Tnf $\alpha$ and macrophage antigen 1 (Mac1) mRNA levels were examined by qPCR analysis, $n=5-6$ (c). Representative images of stained adipose tissue sections, $n=3$. Scale bar represents $20 \mu \mathrm{m}$ (d). WAT Tnf $\alpha$ and $/ 16$ mRNA levels were examined by qPCR analysis, $n=5-6$ (e). One-way ANOVA, $P<0.05$ vs WT within diet. Representative adipocytes with crown-like structures are marked with*.

development. There is, however, no evidence for Gpr1 expression in endothelial cells, lymphocytes, or leukocytes (Edinger et al. 1997, Mognetti et al. 2000, Monnier et al. 2012). In addition, peripheral tissue inflammation, mesenchymal stem cell adipogenesis, and WAT mass were unaffected by Gpr1 loss, indicating that the function of GPR1 within the SVF is probably not in modulation of inflammation or precursor cell differentiation, both established chemerin functions (Muruganandan et al. 2010, 2011, 2013, Issa et al. 2012). Taken together, these results indicate that GPR1 does not contribute to WAT inflammation during obesity or adipogenesis; however, we cannot rule out the possibility that GPR1 plays a specialized role in chemerin-mediated immune or WAT function.

In this study, we found that both Gpr1 HET and KO mice fed on the HFD consumed significantly less food than their WT counterparts, largely as a consequence of reduced meal frequency and size during periods of

Published by Bioscientifica Ltd 
(a)
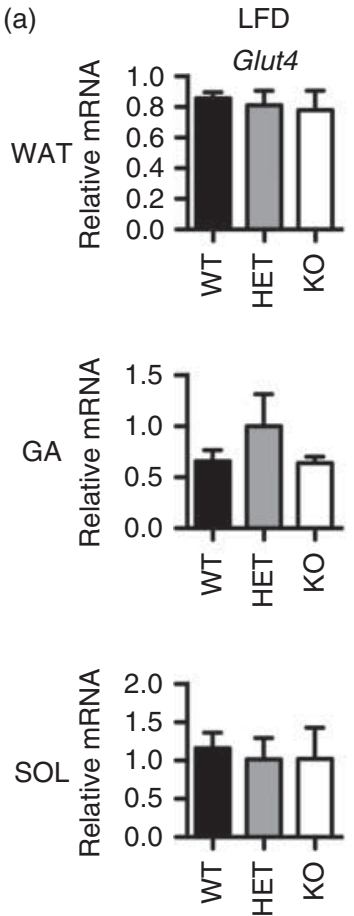
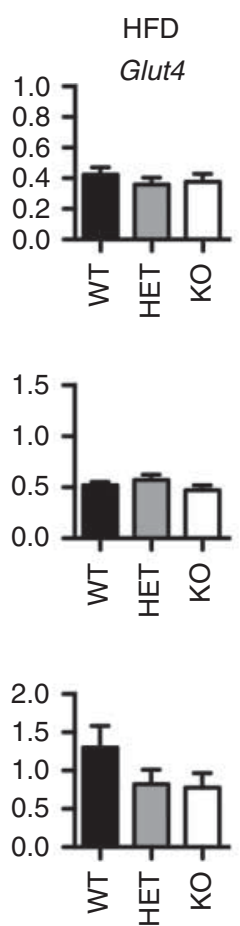

(b)
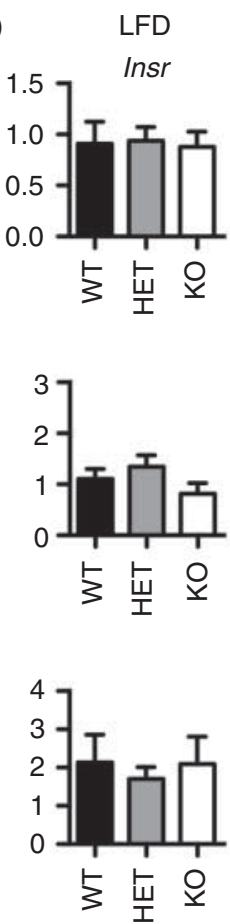
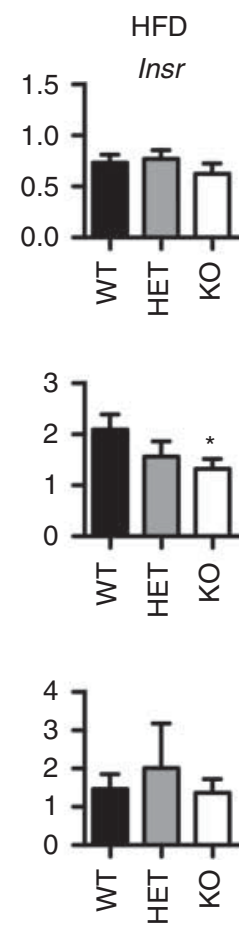

Figure 9

Insulin receptor (INSR) expression is reduced in Gpr1 knockout (KO) mice fed on a high-fat diet (HFD) for 24 weeks. Glucose transporter 4 (Glut4) (a) and INSR (Insr) (b) mRNA expression was measured by qPCR analysis in epididymal white adipose tissue (WAT), gastrocnemius (GA), and soleus
(SOL) muscles of WT, heterozygous (HET), or homozygous KO mice following 24 weeks of feeding with either a low-fat diet (LFD) or a HFD as indicated. One-way ANOVA, ${ }^{*} P<0.05$ vs WT within diet, $n=5-7$.

in feeding in humans. While the mechanism of GPR1mediated feeding modulation remains elusive, these findings reiterate the need for further studies on the role that chemerin and its receptors play in the regulation of feeding and energy balance.

Insulin regulates glucose homeostasis by balancing glucose uptake in peripheral tissues with de novo hepatic glucose production via gluconeogenesis. In obesity, insulin resistance and insulin deficiency are associated with reduced glucose uptake and increased gluconeogenesis. In severe cases, this can lead to pancreatic stress and a decline in insulin secretion, further exacerbating glucose intolerance. Loss of Gpr1 resulted in a detrimental exacerbation of glucose intolerance with obesity. Interestingly, in obese mice, loss of Gpr1 was also associated with severely elevated blood glucose levels following a pyruvate challenge. Similar rates of glucose accumulation and disposal in the PTT indicate that the elevated blood glucose levels in Gpr1 KO mice do not reflect alterations in either gluconeogenesis or glucose uptake respectively. Consistent with this, we observed no change in key gluconeogenic enzymes or the quantity of glucose taken http://joe.endocrinology-journals.org DOI: 10.1530/JOE-14-0069
() 2014 Society for Endocrinology Printed in Great Britain 
up into peripheral tissues $60 \mathrm{~min}$ following a glucose challenge with Gpr1 loss. These data are, however, consistent with a delay in glucose disposal, which could arise as a consequence of insulin resistance in peripheral tissues (WAT, liver, and skeletal muscle) and/or impairment of glucose-stimulated insulin secretion. Clinical, in vivo, and in vitro studies indicate a potential role for the chemerin axis in insulin resistance (Rourke et al. 2013). We found no evidence of altered adipose or liver tissue inflammation or lipid deposition, common features of obesity-associated insulin resistance, indicating that these are probably not contributing to the observed phenotype. With respect to a potential role for Gpr1 in skeletal muscle function, we demonstrated expression of chemerin (Rarres2), Gpr1, and Cmklr1 within the hind limb, indicating that muscle may be both a source and target of chemerin signaling through CMKLR1 and GPR1. Similar expression has been shown previously in mouse GA (Ernst et al. 2010). Coincident with the HFD glucose intolerance, GA muscle Insr mRNA levels were elevated in WT mice. This increase was observed to a lesser extent in both HET and $\mathrm{KO}$ mice, indicating that failure to upregulate Insr expression in skeletal muscle with a HFD may contribute to exacerbated insulin resistance in $\mathrm{KO}$ mice. A similar pattern of Insr expression was observed previously in Cmklr1 KO mice, which also exhibit glucose intolerance (Ernst et al. 2012). Gpr1 loss could also be contributing to dysfunctional skeletal muscle metabolism through alteration of the chemerin axis as we detected decreased Cmklr1 and chemerin mRNA expression in KO soleus and GA respectively. These changes were not sufficient to alter circulating chemerin levels, but could contribute to local changes in chemerin secretion in the muscle.

Previous studies have implicated chemerin as a positive regulator of pancreatic insulin secretion (Takahashi et al. 2011). In this study, Gpr1 loss was associated with reduced glucose-stimulated insulin release in the context of the HFD. Furthermore, Gpr1 KO mice had lower fasting insulin levels after chronic feeding of the HFD. Given that no difference was observed in pancreatic insulin content, it is most likely that Gpr1 KO mice are deficient in glucose-evoked pancreatic insulin release rather than in insulin synthesis or $\beta$-cell development. While Gpr1 KO mice exhibited higher peak glucose levels in the GTT and PTT, the rate at which glucose was cleared from the blood did not differ between genotypes. Taken together, these data indicate that Gpr1 KO mice exhibit a delayed glucose uptake response to the elevated blood glucose levels produced in these tests. As there were no obvious differences in insulin sensitivity between genotypes, this may have been a consequence of the combined effects of reduced insulin release, or changes in INSR signaling and decreased skeletal muscle Insr expression. While the precise mechanism remains to be elucidated, it is clear that the effects of Gpr1 loss on pancreatic insulin release and glucose uptake are contextual and become apparent only in the presence of obesity and insulin resistance.

It is well established that following secretion chemerin is cleaved by a variety of proteases to generate chemerin peptides with varying degrees of activity (Zabel et al. 2005, Guillabert et al. 2008, Parlee et al. 2012). The finding that certain isoforms may be selectively elevated in localized sites of inflammation indicates that the nature of chemerin function in a given disease state probably depends upon the profile of chemerin isoforms present (Zhao et al. 2011). Which chemerin isoforms are elevated in obesity is unknown; however, it is possible that GPR1 function is essential in obese but not lean mice because it serves as a functional receptor for isoforms that predominate in obesity. Alternatively, Huang et al. (2010) postulated that Cmklr1 and Gpr1 might have diverged subsequent to a gene duplication event, suggesting the possibility of some redundancy in receptor functions. Given that Cmklr1 and chemerin (Rarres2) expression were altered in skeletal muscles in Gpr1 KO mice, we cannot rule out the possibility that changes in chemerin activation of Cmklr1 in the Gpr1 KO mice compensated for the loss of GPR1 function. As such, metabolic evaluation of Gpr1/Cmklr1 double KO mice could provide further insight into the role that these receptors play in regulating chemerin function.

In summary, we report for the first time that the generation and metabolic phenotyping of mice lacking the active chemerin receptor GPR1. This study provides further support the hypothesis that a functional chemerin system is required for the maintenance of healthy glucose homeostasis during obesity. Loss of Gpr1 in vivo alters food consumption and results in glucose intolerance in obese mice. In humans, elevations in circulating chemerin correlate with obesity, inflammation, and diabetes risk; however, no studies to date have examined GPR1 expression or function in humans in any detail. Given that mouse GPR1 shares $47 \%$ amino acid identity with human GPR1, consideration of GPR1 as a functional chemerin receptor in WAT, skeletal muscle, satiety, and glucose homeostasis in future studies using both mice and humans could help clarify the complex role chemerin plays in metabolic function.

Published by Bioscientifica Ltd. 


\section{Declaration of interest}

The authors declare that there is no conflict of interest that could be perceived as prejudicing the impartiality of the research reported.

\section{Funding}

This work was supported by the Canadian Institutes of Health Research (CIHR). J L R is supported by a CIHR-Canada Graduate Scholarships (CGS) award. H J D is supported by a Natural Sciences and Engineering Research Council (NSERC)-CGS scholarship. J L R and H J D are supported by Izaak Walton Killam Predoctoral Scholarships.

\section{Acknowledgements}

The authors are grateful to Dr Matthew Ernst, Dr Sebastian Parlee, Kay Murphy, and the Dalhousie Histology and Research Services laboratory for their technical support.

\section{References}

Albanesi C, Scarponi C, Pallotta S, Daniele R, Bosisio D, Madonna S, Fortugno P, Gonzalvo-Feo S, Franssen JD, Parmentier M et al. 2009 Chemerin expression marks early psoriatic skin lesions and correlates with plasmacytoid dendritic cell recruitment. Journal of Experimental Medicine 206 249-258. (doi:10.1084/jem.20080129)

Barnea G, Strapps W, Herrada G, Berman Y, Ong J, Kloss B, Axel R \& Lee KJ 2008 The genetic design of signaling cascades to record receptor activation. PNAS 105 64-69. (doi:10.1073/pnas.0710487105)

Becker M, Rabe K, Lebherz C, Zugwurst J, Goke B, Parhofer KG, Lehrke M \& Broedl UC 2010 Expression of human chemerin induces insulin resistance in the skeletal muscle but does not affect weight, lipid levels, and atherosclerosis in LDL receptor knockout mice on high-fat diet. Diabetes 59 2898-2903. (doi:10.2337/db10-0362)

Bozaoglu K, Bolton K, McMillan J, Zimmet P, Jowett J, Collier G, Walder K \& Segal D 2007 Chemerin is a novel adipokine associated with obesity and metabolic syndrome. Endocrinology 148 4687-4694. (doi:10.1210/ en.2007-0175)

Brunetti L, Di Nisio C, Recinella L, Chiavaroli A, Leone S, Ferrante C, Orlando G \& Vacca M 2011 Effects of vaspin, chemerin and omentin-1 on feeding behavior and hypothalamic peptide gene expression in the rat. Peptides 32 1866-1871. (doi:10.1016/j.peptides.2011.08.003)

Brunetti L, Orlando G, Ferrante C, Recinella L, Leone S, Chiavaroli A, Di Nisio C, Shohreh R, Manippa F, Ricciuti A et al. 2014 Peripheral chemerin administration modulates hypothalamic control of feeding. Peptides 51 115-121. (doi:10.1016/j.peptides.2013.11.007)

Chakaroun R, Raschpichler M, Kloting N, Oberbach A, Flehmig G, Kern M, Schon MR, Shang E, Lohmann T, Dressler M et al. 2012 Effects of weight loss and exercise on chemerin serum concentrations and adipose tissue expression in human obesity. Metabolism 61 706-714. (doi:10.1016/j. metabol.2011.10.008)

Cinti S, Mitchell G, Barbatelli G, Murano I, Ceresi E, Faloia E, Wang S, Fortier M, Greenberg AS \& Obin MS 2005 Adipocyte death defines macrophage localization and function in adipose tissue of obese mice and humans. Journal of Lipid Research 46 2347-2355. (doi:10.1194/jlr. M500294-JLR200)

Edinger AL, Mankowski JL, Doranz BJ, Margulies BJ, Lee B, Rucker J, Sharron M, Hoffman TL, Berson JF, Zink MC et al. 1997 CD4independent, CCR5-dependent infection of brain capillary endothelial cells by a neurovirulent simian immunodeficiency virus strain. PNAS 94 14742-14747. (doi:10.1073/pnas.94.26.14742)

Edinger AL, Hoffman TL, Sharron M, Lee B, O'Dowd B \& Doms RW 1998 Use of GPR1, GPR15, and STRL33 as coreceptors by diverse human immunodeficiency virus type 1 and simian immunodeficiency virus envelope proteins. Virology 249 367-378. (doi:10.1006/viro.1998.9306)

Ernst MC, Issa M, Goralski KB \& Sinal CJ 2010 Chemerin exacerbates glucose intolerance in mouse models of obesity and diabetes. Endocrinology 151 1998-2007. (doi:10.1210/en.2009-1098)

Ernst MC, Haidl ID, Zuniga LA, Dranse HJ, Rourke JL, Zabel BA, Butcher EC \& Sinal CJ 2012 Disruption of the chemokine-like receptor-1 (CMKLR1) gene is associated with reduced adiposity and glucose intolerance. Endocrinology 153 672-682. (doi:10.1210/en.2011-1490)

Farzan M, Choe H, Martin K, Marcon L, Hofmann W, Karlsson G, Sun Y, Barrett P, Marchand N, Sullivan N et al. 1997 Two orphan seventransmembrane segment receptors which are expressed in CD4-positive cells support simian immunodeficiency virus infection. Journal of Experimental Medicine 186 405-411. (doi:10.1084/jem.186.3.405)

Goralski KB, McCarthy TC, Hanniman EA, Zabel BA, Butcher EC, Parlee SD, Muruganandan S \& Sinal CJ 2007 Chemerin, a novel adipokine that regulates adipogenesis and adipocyte metabolism. Journal of Biological Chemistry 282 28175-28188. (doi:10.1074/jbc.M700793200)

Gruben N, Aparicio Vergara M, Kloosterhuis NJ, van der Molen H, Stoelwinder S, Youssef S, de Bruin A, Delsing DJ, Kuivenhoven JA, van de Sluis B et al. 2014 Chemokine-like receptor 1 deficiency does not affect the development of insulin resistance and nonalcoholic fatty liver disease in mice. PLOS ONE 9 e96345. (doi:10.1371/journal.pone. 0096345)

Guillabert A, Wittamer V, Bondue B, Godot V, Imbault V, Parmentier M \& Communi D 2008 Role of neutrophil proteinase 3 and mast cell chymase in chemerin proteolytic regulation. Journal of Leukocyte Biology 84 1530-1538. (doi:10.1189/jlb.0508322)

Hart R \& Greaves DR 2010 Chemerin contributes to inflammation by promoting macrophage adhesion to VCAM-1 and fibronectin through clustering of VLA-4 and VLA-5. Journal of Immunology 185 3728-3739. (doi:10.4049/jimmunol.0902154)

Hausman DB, Park HJ \& Hausman GJ 2008 Isolation and culture of preadipocytes from rodent white adipose tissue. Methods in Molecular Biology 456 201-219. (doi:10.1007/978-1-59745-245-8_15)

Huang J, Zhang J, Lei T, Chen X, Zhang Y, Zhou L, Yu A, Chen Z, Zhou R \& Yang Z 2010 Cloning of porcine chemerin, ChemR23 and GPR1 and their involvement in regulation of lipogenesis. BMB Reports 43 491-498. (doi:10.5483/BMBRep.2010.43.7.491)

Issa ME, Muruganandan S, Ernst MC, Parlee SD, Zabel BA, Butcher EC, Sinal CJ \& Goralski KB 2012 Chemokine-like receptor 1 regulates skeletal muscle cell myogenesis. American Journal of Physiology. Cell Physiology 302 C1621-C1631. (doi:10.1152/ajpcell.00187.2011)

Kralisch S, Weise S, Sommer G, Lipfert J, Lossner U, Bluher M, Stumvoll M \& Fasshauer M 2009 Interleukin-1 $\beta$ induces the novel adipokine chemerin in adipocytes in vitro. Regulatory Peptides $\mathbf{1 5 4}$ 102-106. (doi:10.1016/j.regpep.2009.02.010)

Lehrke M, Becker A, Greif M, Stark R, Laubender RP, von Ziegler F, Lebherz C, Tittus J, Reiser M, Becker C et al. 2009 Chemerin is associated with markers of inflammation and components of the metabolic syndrome but does not predict coronary atherosclerosis. European Journal of Endocrinology 161 339-344. (doi:10.1530/EJE-09-0380)

Livak KJ \& Schmittgen TD 2001 Analysis of relative gene expression data using real-time quantitative PCR and the $2^{-\Delta \Delta C}$ T method. Methods $\mathbf{2 5}$ 402-408. (doi:10.1006/meth.2001.1262)

Lolmede KDC, Zakaroff-Girard A \& Bouloumie A 2011 Immune cells in adipose tissue: key players in metabolic disorders. Diabetes \& Metabolism Journal 4 283-290. (doi:10.1016/j.diabet.2011.03.002)

Marchese A, Cheng R, Lee MC, Porter CA, Heiber M, Goodman M, George SR $\&$ O'Dowd BF 1994a Mapping studies of two G protein-coupled receptor genes: an amino acid difference may confer a functional variation between a human and rodent receptor. Biochemical and Biophysical Research Communications 205 1952-1958. (doi:10.1006/ bbrc.1994.2899)

Marchese A, Docherty JM, Nguyen T, Heiber M, Cheng R, Heng HH, Tsui LC, Shi X, George SR \& O'Dowd BF $1994 b$ Cloning of human genes encoding 
novel G protein-coupled receptors. Genomics 23 609-618. (doi:10.1006/ geno.1994.1549)

Mognetti B, Moussa M, Croitoru J, Menu E, Dormont D, Roques P \& Chaouat G 2000 HIV-1 co-receptor expression on trophoblastic cells from early placentas and permissivity to infection by several HIV-1 primary isolates. Clinical and Experimental Immunology 119 486-492. (doi:10.1046/j.1365-2249.2000.01149.x)

Monnier J, Lewen S, O'Hara E, Huang K, Tu H, Butcher EC \& Zabel BA 2012 Expression, regulation, and function of atypical chemerin receptor CCRL2 on endothelial cells. Journal of Immunology 189 956-967. (doi:10.4049/jimmunol.1102871)

Muruganandan S, Roman AA \& Sinal CJ 2010 Role of chemerin/CMKLR1 signaling in adipogenesis and osteoblastogenesis of bone marrow stem cells. Journal of Bone and Mineral Research 25 222-234. (doi:10.1359/ jbmr.091106)

Muruganandan S, Parlee SD, Rourke JL, Ernst MC, Goralski KB \& Sinal CJ 2011 Chemerin, a novel peroxisome proliferator-activated receptor $\gamma$ $(\operatorname{PPAR} \gamma)$ target gene that promotes mesenchymal stem cell adipogenesis. Journal of Biological Chemistry 286 23982-23995. (doi:10.1074/jbc. M111.220491)

Muruganandan S, Dranse HJ, Rourke JL, McMullen NM \& Sinal CJ 2013 Chemerin neutralization blocks hematopoietic stem cell osteoclastogenesis. Stem Cells 10 2172-2182. (doi:10.1002/stem.1450)

Parlee SD, Ernst MC, Muruganandan S, Sinal CJ \& Goralski KB 2010 Serum chemerin levels vary with time of day and are modified by obesity and tumor necrosis factor- $\alpha$. Endocrinology 151 2590-2602. (doi:10.1210/ en.2009-0794)

Parlee SD, McNeil JO, Muruganandan S, Sinal CJ \& Goralski KB 2012 Elastase and tryptase govern TNF $\alpha$-mediated production of active chemerin by adipocytes. PLOS ONE 7 e51072. (doi:10.1371/journal. pone.0051072)

Parolini S, Santoro A, Marcenaro E, Luini W, Massardi L, Facchetti F, Communi D, Parmentier M, Majorana A, Sironi M et al. 2007 The role of chemerin in the colocalization of NK and dendritic cell subsets into inflamed tissues. Blood 109 3625-3632. (doi:10.1182/blood-2006-08038844)

Regard JB, Sato IT \& Coughlin SR 2008 Anatomical profiling of G proteincoupled receptor expression. Cell 135 561-571. (doi:10.1016/j.cell. 2008.08.040)

Rouger L, Denis GR, Luangsay S \& Parmentier M 2013 ChemR23 knockout mice display mild obesity but no deficit in adipocyte differentiation. Journal of Endocrinology 219 279-289. (doi:10.1530/JOE-13-0106)
Rourke JL, Dranse HJ \& Sinal CJ 2013 Towards an integrative approach to understanding the role of chemerin in human health and disease. Obesity Reviews 14 245-262. (doi:10.1111/obr.12009)

Sell H, Divoux A, Poitou C, Basdevant A, Bouillot JL, Bedossa P, Tordjman J, Eckel J \& Clement K 2010 Chemerin correlates with markers for fatty liver in morbidly obese patients and strongly decreases after weight loss induced by bariatric surgery. Journal of Clinical Endocrinology and Metabolism 95 2892-2896. (doi:10.1210/ jc.2009-2374)

Takahashi M, Takahashi Y, Takahashi K, Zolotaryov FN, Hong KS, Kitazawa R, Iida K, Okimura Y, Kaji H, Kitazawa S et al. 2008 Chemerin enhances insulin signaling and potentiates insulin-stimulated glucose uptake in 3T3-L1 adipocytes. FEBS Letters 582 573-578. (doi:10.1016/ j.febslet.2008.01.023)

Takahashi M, Okimura Y, Iguchi G, Nishizawa H, Yamamoto M, Suda K, Kitazawa R, Fujimoto W, Takahashi K, Zolotaryov FN et al. 2011 Chemerin regulates $\beta$-cell function in mice. Scientific Reports 1123 (doi:10.1038/srep00123)

Tan BK, Chen J, Farhatullah S, Adya R, Kaur J, Heutling D, Lewandowski KC, O'Hare JP, Lehnert H \& Randeva HS 2009 Insulin and metformin regulate circulating and adipose tissue chemerin. Diabetes 58 1971-1977. (doi:10.2337/db08-1528)

Vermi W, Riboldi E, Wittamer V, Gentili F, Luini W, Marrelli S, Vecchi A, Franssen JD, Communi D, Massardi L et al. 2005 Role of ChemR23 in directing the migration of myeloid and plasmacytoid dendritic cells to lymphoid organs and inflamed skin. Journal of Experimental Medicine 201 509-515. (doi:10.1084/jem.20041310)

Wittamer V, Franssen JD, Vulcano M, Mirjolet JF, Le Poul E, Migeotte I, Brezillon S, Tyldesley R, Blanpain C, Detheux M et al. 2003 Specific recruitment of antigen-presenting cells by chemerin, a novel processed ligand from human inflammatory fluids. Journal of Experimental Medicine 198 977-985. (doi:10.1084/jem.20030382)

Zabel BA, Allen SJ, Kulig P, Allen JA, Cichy J, Handel TM \& Butcher EC 2005 Chemerin activation by serine proteases of the coagulation, fibrinolytic, and inflammatory cascades. Journal of Biological Chemistry 280 34661-34666. (doi:10.1074/jbc.M504868200)

Zhao L, Yamaguchi Y, Sharif S, Du XY, Song JJ, Lee DM, Recht LD, Robinson WH, Morser J \& Leung LL 2011 Chemerin158K protein is the dominant chemerin isoform in synovial and cerebrospinal fluids but not in plasma. Journal of Biological Chemistry 286 39520-39527. (doi:10.1074/jbc.M111.258954)

Received in final form 14 May 2014

Accepted 3 June 2014

Accepted Preprint published online 3 June 2014
(C) 2014 Society for Endocrinology Printed in Great Britain 